\title{
Erratum to: Enhancement of device performance by using quaternary capping over ternary capping in strain-coupled InAs/ GaAs quantum dot infrared photodetectors
}

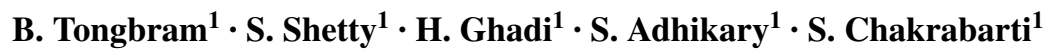

Published online: 20 April 2017

(C) Springer-Verlag Berlin Heidelberg 2017

Erratum to: Appl. Phys. A (2015) 118:511-517

DOI 10.1007/s00339-014-8854-9

The original version of this article unfortunately contained a mistake. The captions to Figs. 3 and 4 were interchanged. The correct versions are given below.

The online version of the original article can be found under doi:10.1007/s00339-014-8854-9.

S. Chakrabarti

subho@ee.iitb.ac.in; subhanandachakrabarti@gmail.com

1 Department of Electrical Engineering, Indian Institute of Technology Bombay, Powai, Mumbai, Maharashtra 400076, India 

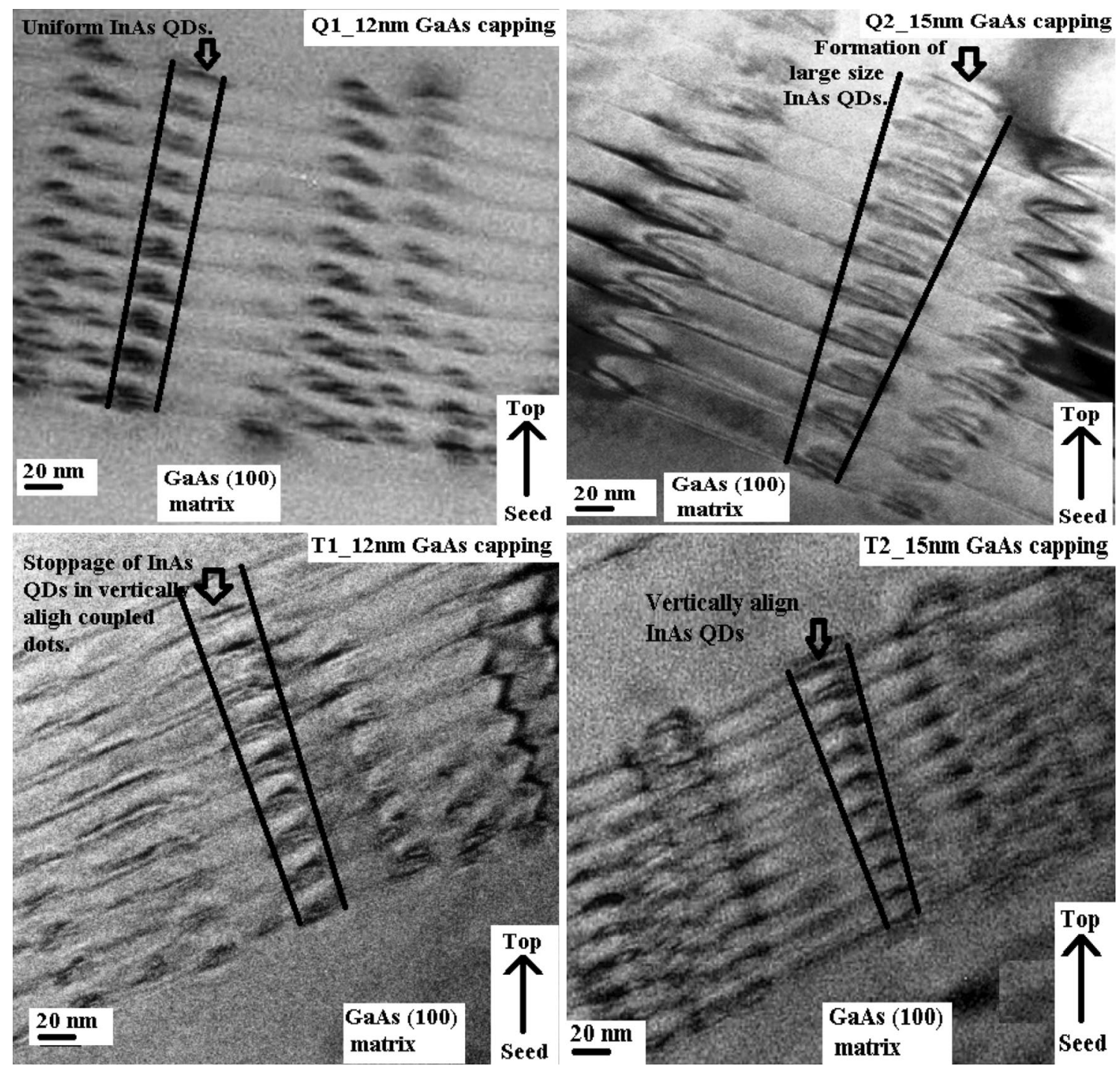

Fig. 3 Cross-sectional TEM images of all coupled samples. The average QD heights were 9, 11, 4, and $5 \mathrm{~nm}$ for samples Q1, Q2, T1, and T2, respectively

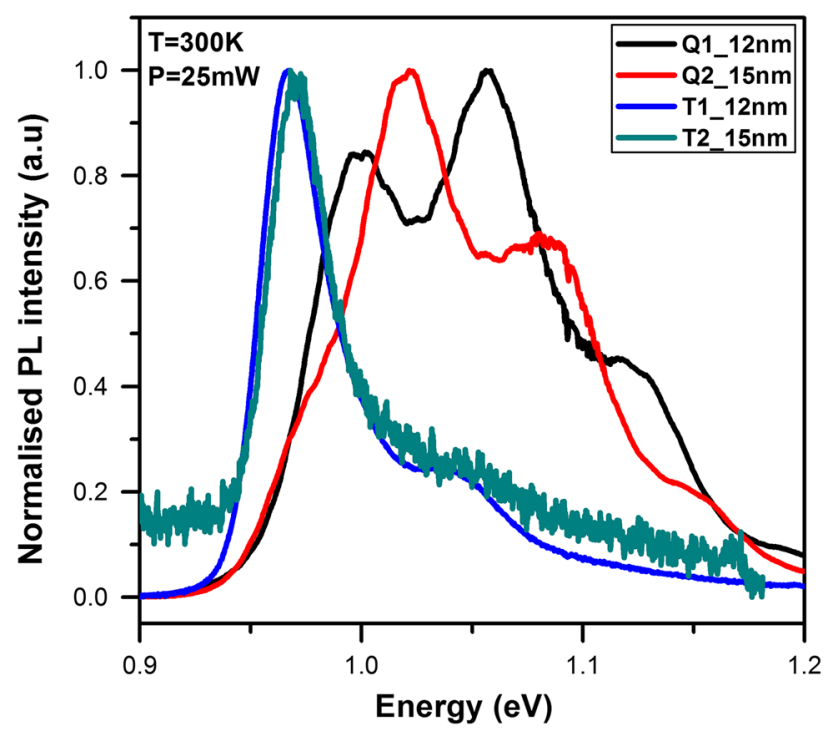

4Fig. 4 Normalized room-temperature (300 K) PL spectra at an excitation power of $25 \mathrm{~mW}$ as a function of energy 